\title{
NOVOS MODOS DE ESCRITA: ALFABETIZAÇÃO SEM ESCRITA CURSIVA
}

\section{NEW MODES OF WRITING: LITERACY WITHOUT CURSIVE WRITING}

\author{
Sinval Martins de Sousa Filho* \\ Pedro Henrique da Silva*
}

\begin{abstract}
Resumo:No presente estudo, visando contribuir com a reflexão sobre a aquisição da escrita na atualidade, apresentamos uma discussão sobre a alfabetização, especialmente sobre os processos que se dão com o aprendizado pelas telas e sem o uso de letra cursiva. também, discorremos sobre os recursos tecnológicos como ferramentas de letramento na contemporaneidade (soares, 2002). objetivamos demonstrar como as escolas brasileiras lidam com o referido tema. para a reflexão proposta, mobilizamos autores como Chartier (2010), Lévy (1998), Soares (2002) e de Lemos (1998) e tratamos de alfabetização, do letramento digital e da formação do sujeito na aquisição da escrita. nossa metodologia centra-se na pesquisa bibliográfica. os resultados demonstram que a alfabetização pela via da escrita cursiva não pode ser de imediato abandonada, mas tudo indica que ela deve ocorrer em paralelo com as atividades de alfabetização no computador.
\end{abstract}

Palavras-chave: Aquisição da escrita. Escrita digital. Escrita cursiva.

\begin{abstract}
In this paper, aiming to contribute to the reflection on the acquisition of writing today, we present a discussion on literacy only on the computer screen, without using cursive letters. Also, we talk about the potential of technological resources as literacy tools that can contribute to extrapole the technical and instrumental dimension of pure writing system domain (SOARES, 2002). We intend to demonstrate how Brazilian schools deal with the theme. For the proposed reflection we mobilized authors as Chartier (2010), Pierre Lévy (1998), Soares (2002), and De Lemos (1998). We deal with the technical categories of writing, digital literacy, cyberculture and subject formation in writing acqusition. Our research is bibliographic study. The results demonstrate that written literacy cannot be immediately abandoned, but must occur in conjunction with computer literacy.
\end{abstract}

Keywords: Writing acquisition. Digital writing. Cursive writing.

\section{Introdução}

Há algum tempo, dedicamo-nos ao estudo acerca da aquisição de língua, especialmente nos detendo em pesquisas sobre processos relativos à aquisição das línguas Xerente e Portuguesa (cf. SOUSA FILHO, 2009; SOUSA FILHO e SILVA, 2017; SILVA, 2018). Na esteira de nossas pesquisas propomos, neste estudo, uma reflexão mais centrada na aquisição da escrita. O recorte feito se justifica pelo fato de estarmos investigando o papel/impacto das Novas Tecnologias de Informação e Comunicação (NTIC) na educação (LIBÂNEO et. al., 2011). Sendo ainda mais específicos, esboçamos parte de um projeto de pesquisa em fase inicial de levantamento bibliográfico sobre alfabetização sem o uso da letra cursiva.

Buscamos investigar o impacto da abolição da escrita cursiva e do seu substituinte nos anos iniciais do processo de alfabetização a partir da escrita digital ou na tela. Entendemos que em um país onde as crianças devem ir para a escola quando completam 4 anos de idade - ou bem menos, pois no Brasil há crianças que vão para a escola a partir de 60 dias de vida -, devemos considerar o processo contínuo entre a

\footnotetext{
* Doutor em Letras e Linguística. Professor da Graduação e Pós-graduação da Faculdade de Letras/UFG. E-mail: sinvalfilho7@gmail.com.

* Doutorando no Programa de Pós-graduação em Letras e Linguística/UFG. Bolsista da Coordenação de Aperfeiçoamento de Pessoal de Nível Superior (CAPES). E-mail:pedrohenriqueletrasufg@gmail.com.
} 
aquisição das duas modalidades de uso de uma língua: a falada e a escrita, entendendo fala e escrita para além da linguagem verbalizada vocalmente e também considerando escritas diferentes da alfabética. Apesar de ter esse contínuo em mente, por questões metodológicas, o foco do trabalho é a aquisição da escrita.

O início da investigação deu-se a partir do conhecimento de que algumas escolas de países como Finlândia e Estados Unidos da América (EUA) já aboliram a escrita cursiva na fase de alfabetização e adotaram o letramento em tela, conforme Guimarães e Silva (2016). Assim, buscamos refletir sobre a viabilidade da aplicação desse modelo no Brasil. Também, objetivamos demonstrar como está a situação brasileira quanto ao tema em questão.

Metodologicamente, pautamo-nos numa pesquisa bibliográfica pelo fato de "a pesquisa bibliográfica ser um apanhado geral sobre os principais trabalhos já realizados, revestidos de importância, por serem capazes de fornecer dados atuais e relevantes relacionados com o tema" (MARCONI; LAKATOS, 2003, p. 158). Ou seja, valemonos basicamente de trabalhos científicos para construção desse texto. Assim, investigamos o que já foi produzido na literatura sobre a temática da aquisição da escrita no viés "padrão" e na escrita em tela. Utilizamos o descritor "aquisição de linguagem em crianças" e consideramos como fonte de coleta os dados trabalhos disponíveis na internet, como banco de teses e dissertações, livros e periódicos publicados no período de 2013 a 2019.

Como suporte teórico, utilizamos Chartier (2010), Lévy (1998), Soares (2002) e De Lemos (1998) para equacionarmos as questões: (r)evolução da escrita, conhecimento coletivo promovido pela cibercultura, as práticas de letramento e, por fim, o efeito da escrita na constituição do sujeito. Reforçamos que não há tópicos específicos neste artigo destinados a cada fonte teórica por haver, dentro das possibilidades, um entrelaçamento das ideias de cada autor, de modo que possamos endossar nossa reflexão sobre o tema.

Após esses primeiros esclarecimentos, partimos para a exploração do tema. Segundo Gonçalves (2020), a letra cursiva se refere à letra manuscrita, a qual é feita correndo a letra sobre o papel e o termo cursivo deriva do latim cursivu-, utilizado para se referir à escrita romana cursiva (também chamada de maiúscula cursiva ou capitalis cursiva), ou seja, a forma quotidiana de escrita à mão, "utilizada na confecção de cartas, por mercadores nos seus relatórios, pelos alunos que estudavam o alfabeto romano e até pelos imperadores nos seus despachos" (GONÇALVES, 2020, p. 1). A característica de ser letra corrida também se aplica ao registro de palavras quando as escritas utilizam os alfabetos latino e cirílico, como acontece quando grafamos a língua portuguesa.

No modelo cursivo da língua portuguesa, as palavras são escritas a partir da ligação das letras que as compõem, fazendo com elas sejam percebidas como resultado de um único traço de escrita. Com o advento da internet, de todo universo virtual e da revolução digital, surgiu a necessidade de nos relacionarmos com novas formas de escrita. De acordo com Chartier (2010, p. 9),

Ao quebrar o vínculo antigo estabelecido entre textos e objetos, entre discursos e sua materialidade, a revolução digital obriga a uma revisão radical dos gestos e das noções que associamos ao escrito. Apesar das inércias do vocabulário, que tentam acomodar a novidade, designando-a com palavras familiares, os fragmentos de textos que aparecem no monitor não são páginas, mas composições singulares e efêmeras. E ao contrário de seus predecessores, rolo ou códex, o livro eletrônico não mais se diferencia pela evidência de sua forma material das outras produções da escrita. 
Assim, surgem novas formas de escrita e de leitura. Para Pedroza e Nicolau (2020), a composição digital se caracteriza pela escrita no teclado ou na tela, sendo que cada letra é teclada separadamente para a formação das palavras, embora fiquem agrupadas morfossintaticamente. A partir do aparecimento da tecnologia touch screenque está presente em tablets, smartphones, iPad etc. - também é possível escrever imediatamente na tela, a partir de toques em teclados virtuais. Conforme os referidos autores,

sabe-se que já somos inteiramente dependentes da tela. Suas mensagens nos conduzem a uma interação que pode ser simplificada através do toque em telas de tecnologia móvel, tendo por principais representantes os e-readers, smartphones e tablets. A mobilidade das mídias é redefinida pela possibilidade de se ter uma maior fluidez comunicacional (PEDROZA; NICOLAU, 2020, p. 69).

$\mathrm{Na}$ esteira dessas mudanças tecnológicas, sendo a escrita uma técnica ou tecnologia que requer um conhecimento prévio, conforme Soares (2002), os EUA aboliram a escrita cursiva e a letra bastão dos processos de alfabetização. Conforme Chao (2020), desde 2011, os alunos norte americanos estão sendo alfabetizados diretamente na tela, a partir do uso de alguma tecnologia móvel.

Em 2015, por sua vez, a Finlândia também aderiu ao movimento de alfabetização a partir do uso da escrita digital ou escrita em tela (GUIMARÃES E SILVA, 2016). No Brasil, segundo Padgurschi (2020), há algumas escolas no estado de São Paulo que iniciaram, em 2017, projetos de implementação da alfabetização em tela, porém sem deixar de lado o modelo tradicional, ou seja, trata-se de uma alfabetização concomitante em que se usa o molde clássico e o digital.

Feitas essas breves considerações sobre a escrita, sua vinculação aos processos de alfabetização e de letramento, anunciamos de onde partimos para tratar da abolição da escrita à mão, para refletirmos sobre a alfabetização sem escrita cursiva.

\section{Por uma ideia de escritas concebidas como línguas vivas}

A escrita, pouco ou muito, encontra-se no mundo da criança sobre diferentes suportes (...). A língua escrita vive. A língua escrita está viva. A língua fala (BRAGGIO, 2015, p. 140/141).

Tradicionalmente, a escrita tem sido usada para caracterizar tempos da história da humanidade. A sua invenção, segundo Frévier (1948) e Chartier (2010), atesta a passagem do homem da Pré-História para a História. Nesse sentido, parece-nos que a cada nova forma adquirida pela escrita temos uma nova sociedade, um novo tempo ou vice-versa.

Neste artigo, nosso interesse não está em recuperar a história da escrita, apesar de sabermos que esse tema tangencia nossa reflexão. Apontamos, na medida do necessário, alguns tópicos da referida história e a ela relacionados a fim de contextualizar a escrita e seu conceito. Vale ressaltar, de imediato, que, de acordo com Février (1948), as formas de escrita não são simplesmente uma pura e simples notação do pensamento. Elas são mais do que isso. Saussure (1996) e De Lemos (1998) consideram que a escrita é um ato que produz efeitos que se dão sobre/no/com o sujeito.

A escrita, para Saussure (1996), é similar à língua, mas não se confunde com ela, uma vez que "a língua tem, pois, uma tradição oral independente da escrita e bem 
diversamente fixa" (SAUSSURE, 1996, p. 35). Em vista disso, Saussure considera que a língua tem vida própria e independente da forma escrita. Porém, o referido linguista reconhece que um conjunto de caracteres pode servir à representação gráfica da língua, pois ela [a escrita] se configura como um sistema de imagens convencionais usadas para registrar e fixar a língua, ainda que a representação seja parcial, uma vez que, segundo o mestre genebrino, não é possível que a escrita represente graficamente tudo o que se diz.

Assim, para Saussure (1996), a escrita é um sistema composto por signos arbitrários, não sendo, portanto, a letra, uma representação fidedigna do som, pois não há uma relação direta entre ambos. No sistema da escrita, o valor é estabelecido pela característica das letras, que são negativas e diferenciais e estão em oposição umas às outras. Um número limitado de letras compõe o sistema de escrita, não importando a forma como as letras/palavras são postas. Enfim, sendo o sistema de representação gráfica da língua, a escrita pode fixá-la "em imagens convencionais, ao passo que seria impossível fotografar em todos os seus pormenores os atos da fala" (SAUSSURE, 1996, p. 23).

Seguindo a linha de pensamento de Saussure (1996), De Lemos (1998) afirma que a escrita é um sistema próprio que, dentro de condições sociais, dialoga com a língua oral. Para ela, a escrita não deve ser vista como uma transcrição da oralidade ou como representação dos sons da fala, sobretudo, porque não há nada na escrita em si que remeta para a materialidade sonora da fala. Assim, a linguista considera que a aquisição da linguagem escrita se dá por meio das práticas discursivas de modo análogo à aquisição da língua oral, ou seja, no processo aquisicional o Outro tem o papel de intérprete e a língua/gem escrita surge como elemento que forma o sujeito.

Desta feita, para De Lemos (1998, p. 21):

Ao tratar a aquisição da escrita, assim como a aquisição de linguagem em geral, como transformação ou mudança que se opera através do funcionamento simbólico, o que tenho em mente é sujeito e objeto (para um sujeito) como efeitos desse funcionamento. Isso significa que não se parte da interação sujeito-e-objeto, mas da linguagem. Isso significa que não se chega a um sujeito que se apropria do objeto a um certo ponto de seu percurso, que faz dele um conhecimento, um saber estável que o esgota. A cada ato/acontecimento de leitura/escrita se pode refazer essa relação nesse funcionamento.

Cabe mencionar que Chartier (2010) afirma que a revolução digital inaugurou novas formas de escrita e, portanto, de leitura. Na visão de Chartier, para entendermos a (r)evolução na cultura escrita, precisamos conhecer bem as outras revoluções ocorridas nesse campo. Para tanto, o historiador francês sugere que devemos mergulhar nas histórias do aparecimento do códex, da invenção da imprensa e das transformações das práticas de leitura na Idade Média, no século XVIII ou nas sociedades do século XIX.

Chartier (2010) considera que a escrita digital exige das sociedades contemporâneas uma mudança nos gestos e nas noções tradicionais relacionadas à escrita. Para tanto, é preciso entender que no monitor os textos não surgem como páginas, mas como composições efêmeras, o que faz com que tenhamos textos descontínuos e escritas esparsas.

Assim, segundo Chartier (2010), a lógica cultural da textualidade digital nos convida à recomposição irrestrita de fragmentos obtidos em bancos de dados computacionais, quaisquer que sejam as suas naturezas. Assim, a escrita tecnológica inaugura um tempo em que impera os textos abertos, feitos por/de fragmentos indefinidamente recompostos, isto é, a escrita digital - ou "escritura originalmente 
digital - que permite, por sua vez, inventar relações com a escrita efetivamente original, livres dos constrangimentos dos direitos de autor e da página impressa" (CHARTIER, 2014 apud MAGALHÃES, 2014, p. 421).

Há uma geração de crianças e adolescentes que estão crescendo em meio ao avanço cada vez mais rápido das NTIC, portanto, há a necessidade da discussão do letramento digital, que está diretamente ligado ao papel da escola de alfabetizar e letrar pessoas. Sabemos que há uma gama de autores que colocam a alfabetização e o letramento em instâncias diferentes. Entretanto, para o desenvolvimento deste trabalho, temos como norte apenas as considerações acerca do que é letramento.

Concordamos com Soares (2002, p. 151) que o letramento digital é um "estado ou condição que adquirem os que se apropriam da nova tecnologia digital e exercem práticas de leitura e de escrita na tela." De forma a ampliar tal conceito, para além da escrita convencional, apoiamo-nos em Theisen (2015), a qual considera que:

O letramento digital vai além de manusear as ferramentas, ser letrado digitalmente representa a realização de modos de leitura e de escrita em situações que envolvem textos, imagens e sons em um novo formato, tendo como suporte o ambiente digital. O letramento digital proporciona a inserção das pessoas em práticas sociais por meio das ferramentas tecnológicas, colaborando para desenvolver um posicionamento crítico sobre o uso das mesmas e a sua atuação na sociedade (THEISEN, 2015, p. 42).

O ponto em comum entre os conceitos de Soares (2002) e Theisen (2015) centra-se na ideia do letramento digital como forma de inserção nas práticas sociais.

A seguir, buscamos aprofundar a discussão sobre tipos de letras e o letramento digital, dando enfoque para a problematização das práticas de alfabetização/letramento com letra cursiva pela via clássica e tendo como suporte os meios tecnológicos, como computador, por exemplo. A intenção é promover uma discussão-reflexão no trato que o Brasil oferece ao assunto do letramento digital em comparação com outros países, como Finlândia e Estados Unidos da América. Nos países citados, o letramento digital leva em consideração que a forma como se dá o letramento ativa algumas regiões do cérebro. Dessa forma, o que se avalia é a prática social, afinal, estamos mencionando duas sociedades cujo papel da tecnologia no cotidiano é indispensável, ao passo que no Brasil, apesar de sermos um país com boa abrangência tecnológica, ainda não superamos algumas discussões sobre a diferença entre letramento e alfabetização.

\section{A obrigatoriedade internacional da escrita à mão e/ou da escrita digital nas escolas de alfabetização}

Existe na internet, rede mundial de computadores, um canal aberto para a discussão sobre alfabetização e letramento. Esse site, desde 2015, quando foi lançado, tem sido muito acessado por professores interessados em saber mais sobre como ocorre o processo de ensino-aprendizagem da língua portuguesa na escola. O Centro de alfabetização, leitura e escrita - Ceale/UFMG disponibilizou no site da universidade ${ }^{1}$ um canal intitulado "Magda Soares responde", especialmente para que as pessoas pudessem se informar acerca do tema alfabetização e letramento. Uma das principais perguntas

\footnotetext{
${ }^{1}$ Disponível em: <http://www.ceale.fae.ufmg.br/pages/view/magda-soares-responde-5.html>. Acesso em: 23 jun. 2020.
} 
recorrentes feitas à Magda refere-se às dúvidas sobre o dever de alfabetizar a partir da letra cursiva ou da letra bastão ${ }^{2}$.

No rol de perguntas, não há nenhuma referente à abolição da escrita à mão nos processos de alfabetização das escolas brasileiras. Ainda que perguntas com essa temática não tenham sido feitas, Soares (2020), atenta ao que ocorre no mundo, adianta o assunto em uma das respostas dadas às professoras, conforme pode ser depreendido abaixo:

Minha maior dúvida é se ainda é importante trabalhar a letra cursiva na alfabetização - M.A.A.M. - E. E. República Riograndense - Piratini - RS.

Posso permitir que, mesmo no $3^{\circ}$ ano, apesar de conhecerem as duas escritas, meus alunos continuem com a escrita da letra palito, ou devo cobrar o uso da letra cursiva? - Z.M.S.V. - E. M. Zeferino Antunes de Almeida - Entre-Ijuís - RS.

Quando as professoras perguntam se ainda é importante trabalhar a letra cursiva, se a criança pode optar por não usar a letra cursiva, está subjacente às perguntas o reconhecimento de que a letra cursiva vem sendo cada vez menos usada, porque realmente a tendência é que a tecnologia leve as pessoas a digitarem mais que a escreverem com lápis e papel. Mas acho que ainda é cedo para acreditar que, em curto prazo, as pessoas não vão mais escrever à mão, embora em alguns países já esteja sendo retirado da escola oficialmente o ensino da letra cursiva. Eu não sou tão avançada assim para concordar com isso... acho que a cursiva ainda é necessária em várias situações, nas práticas cotidianas. No entanto, é preciso reconhecer que, se antigamente era realmente necessário que a criança dominasse a cursiva, e eram comuns as aulas de caligrafia, hoje em dia cada vez menos esse ensino é necessário; mas é importante que a criança pelo menos saiba ler um texto em letra cursiva, porque ela vai se deparar muitas vezes com textos em cursiva. Por outro lado, o que é interessante é que o ensino da cursiva, se não for entendido como ensino de caligrafia, é quase desnecessário, porque as crianças passam quase naturalmente para a cursiva, muito por influência da família, sobretudo crianças das escolas públicas, com menos acesso às tecnologias. Pode haver uma orientação da professora, mas penso que quase se pode deixar isso por conta da criança, e penso que se pode não exigir a cursiva. $\mathrm{O}$ que se deve cobrar é que a escrita seja legível porque, se a escrita é uma forma de comunicação, ela tem de possibilitar que o outro consiga ler o que é comunicado.

Na visão de Soares (2020), a letra bastão deve ser a mais usada porque ela apresenta maior correspondência com os fonemas, pelo menos no que se refere ao fato de que cada letra, assim como o fonema, se apresenta como um elemento individual (ainda que o fonema seja visto como resultado de um feixe de traços). Essa característica faz com que a criança tenha consciência fonológica-gráfica das representações dos signos pela escrita, da representação conjunta explicitada na letra-

\footnotetext{
${ }^{2}$ Segundo Dante (2019, p. 29), os "trabalhos na área da educação com frequência alternam termos como 'letra de fôrma', 'letra de imprensa', 'letra bastão', 'letra script' e 'letra palito' para fazer referência a alfabetos em letras soltas maiúsculas e minúsculas”. Já as letras cursivas, classificadas em maiúsculas e minúsculas, são conhecidas como letras emendadas ou ligadas e se caracterizam "por iniciarem no mesmo lugar (início da linha), potencializarem a personalização da letra e facilitarem a identificação da palavra como unidade gramatical” (DANTE, 2019, p. 30).
} 
fonema. Desta forma, adianta Soares (2020), a criança já estará preparada para a escrita no computador, para a escrita digital.

Vale lembrar que a alfabetização é compreendida como o processo pelo qual se adquire o domínio de um código bem como das habilidades necessárias para ler e escrever. Tendo em vista essa concepção, é preciso que haja o domínio de uma tecnologia (de um conjunto de técnicas para sermos mais exatos) para que ocorra o exercício da escrita. Por sua vez, o exercício competente da tecnologia da escrita no contexto social é denominado letramento, que, segundo Soares (2002, p. 65), "é o estado ou condição de quem não só sabe ler e escrever, mas exerce as práticas sociais de leitura e de escrita que circulam na sociedade em que vive".

Uma pergunta precisa ser feita: qual seria a diferença entre uma pessoa alfabetizada e uma pessoa alfabetizada e letrada? A resposta, de acordo com Soares (2002), é: alfabetizado é quem adquiriu a tecnologia de escrita a ponto de saber decodificar os sinais gráficos da língua de seu país, porém ainda não possui a habilidade de ler e de escrever. Apesar de o sujeito ter passado pela escola, ainda lê com extrema dificuldade, na maioria dos casos de modo muito superficial, e escreve com pouca frequência. Do outro lado do contínuo está a pessoa letrada ou alfabetizada e letrada, isto é, aquela que sabe lidar bem com a leitura e a escrita de acordo com as práticas sociais que as constituem.

Para Barton e Hamilton (1998), o letramento é uma prática cultural, sócio e historicamente estabelecida. $\mathrm{O}$ indivíduo plenamente letrado tem a capacidade de ver além do que está representado pelo código de sua língua, ou seja, o cidadão letrado é capaz de relacionar informações que não estão claramente postas no texto falado ou escrito e vinculá-las à sua realidade histórica, social e política. Assim, em conformidade com Barton e Hamilton (1998, p. 9):

Letramento não é o mesmo em todos os contextos; ao contrário, há diferentes Letramentos. A noção de diferentes letramentos tem vários sentidos: por exemplo, práticas que envolvem variadas mídias e sistemas simbólicos, tais como um filme ou computador, podem ser considerados diferentes letramentos, como letramento fílmico e letramento computacional (computer literacy).

Sob essa ótica fica mais fácil compreender o motivo que levou, ou favoreceu, por exemplo, a Finlândia a abolir a escrita à mão e aderir ao letramento digital. Afinal, estamos falando de uma nação de destaque no que se refere ao desempenho dos estudantes na prova do Programa Internacional de Avaliação de Alunos - PISA ${ }^{3}$, além de ser um país cuja desigualdade entre as escolas públicas e privadas é mínima. Obviamente, o sucesso da Finlândia está associado, também, a fatores políticos, sociais, econômicos e culturais, que precisam ser destacados quando ocorre a comparação com outras nações.

De acordo com Bibiano (2020), outro fator que motivou a Finlândia a adotar a escrita digital na alfabetização diz respeito à ideia de que a escrita cursiva é uma representação cultural que não impacta o desenvolvimento cerebral das crianças. Tanto essa ideia quanto a de que o desenvolvimento da área específica pela linguagem não tem relação com o tipo de letra que usa para representar a escrita, uma vez que "essa área do

\footnotetext{
${ }^{3} \mathrm{O}$ exame avalia as habilidades desenvolvidas pelos estudantes em três campos, a saber: leitura, matemática e ciências. A intenção é verificar o nível de preparo dos jovens de cada país, quando completam a escolaridade considerada indispensável, para enfrentar os desafios postos pela sociedade do conhecimento. (BRASIL, 2020).
} 
cérebro [lado esquerdo] se desenvolve com a escrita à mão, mas não porque ela é feita com um tipo de letra específica, e sim pela atividade mental exercida nessa função" (RELVAS apud BIBIANO, 2020, p. 1).

Guimarães e Silva (2016, p. 2787) atestam que

Na Finlândia, a partir de setembro de 2015, as crianças que ingressaram no ensino fundamental foram as últimas a ter aulas de caligrafia no país; até setembro de 2016, as aulas de caligrafia deverão ser substituídas por aulas de computação.

Ainda de acordo com Guimarães e Silva (2016), uma das justificativas plausíveis usadas para dispensar a troca da letra à mão pela digitação nas escolas finlandesas centra-se na ideia de que a ilegibilidade da grafia dos alunos e o tempo despendido com o ensino da letra cursiva atrapalham $o$ processo de alfabetização/letramento mais do que ajuda.

Se no contexto europeu apenas a Finlândia iniciou o processo de letramento em tela, Chao (2020) sinaliza que, em 2011, 40 estados dos EUA aboliram a obrigatoriedade das escolas de alfabetizar a partir da escrita à mão. Com isso, o governo americano - a partir do Common Core State Standard, que é o órgão voltado para a padronização do currículo comum - autorizou as escolas iniciarem a alfabetização das crianças a partir da escrita digital. Chao (2020, p. 1) afirma que

O Estado de Indiana, nos Estados Unidos, adotou, em julho [de 2011], o Common Core State Standard, uma iniciativa de padronização do ensino básico que torna o ensino da letra cursiva opcional, passível de ser abolido futuramente. Para os defensores do padrão, a letra de forma deve receber prioridade no ensino, uma vez que as crianças utilizam cada vez mais computadores. Também é mais fácil para o jovem associar os símbolos das teclas às letras do que desenhar a palavra. A decisão trouxe novamente à tona a discussão sobre o desaparecimento da letra de mão.

Segundo Guimarães e Silva (2016), o que motivou os EUA a adotar a alfabetização a partir do computador foi o fato de que as crianças, ditas nativas digitais, quase nunca usam o papel e o lápis, uma vez que a maioria de suas atividades e trabalhos escolares é feita mediante o uso de um computador. Assim, é mais significativo e coerente que elas aprendam a ler e a escrever a partir de recursos digitais usados nas escolas americanas, que levam em conta o progresso que ocorre nessa sociedade.

Cabe ressaltar, porém, que toda mudança traz algum receio, alguma resistência. Nesse sentido, vemos a "insistência" da escrita à mão em permanecer como protagonista nos processos de alfabetização de algumas escolas americanas. Essa permanência (ou a volta da escrita cursiva) pode ser vista em movimentos que vêm ocorrendo nos EUA seis anos após os governos dos estados americanos terem "abolido" a escrita à mão das salas de alfabetização.

Segundo Yow (2020), o Estado da Louisiana e outros 13 estados americanos decidiram que a escrita cursiva, a escrita à mão, deve voltar às escolas de alfabetização. Segundo consta no site da Southern Regional Education Board (SREB) ${ }^{4}$, a volta da 
escrita à mão para as escolas é fruto de um clamor popular. Após uma pesquisa quantitativa, o SREB demonstrou como foram feitas as movimentações populares para que as autoridades legais fizessem voltar às escolas a escrita à mão. Na Louisiana, a lei entrou em vigor no dia 01 julho de 2017.

Hennelly (2020) menciona que nos estados do Alabama e da Louisiana não só se recomenda que a escrita à mão volte aos bancos escolares como também a partir de julho de 2017 foi cobrado dos alunos uma chamada proficiência cursiva, o que, de acordo com o pesquisador, significa a volta das aulas de caligrafia. Essas cobranças serão exigidas dos alunos no jardim de infância até a quinta série no Alabama, na Louisiana, em Ohio, em Illinois, em Delaware, em Nova Iorque e na Califórnia.

De acordo com Hennelly (2020), o retorno da letra cursiva se dá por razões sentimentais. Desta forma, ele afirma que "é a beleza artística da escrita cursiva ou caligrafia que inspira. E então, é claro, há o tempo dos velhos tempos, com alguns pais querendo que seus filhos aprendam isso porque eles próprios tiveram que, portanto, conectar as gerações" (HENNELLY 2020, p. 2).

Segundo Matthews (2020, p. 1), citando a fala de uma aluna, a escrita à mão deve continuar na escola porque ela permanece na sociedade:

Definitivamente não é necessário, mas acho que é legal ter isso, disse Emily Ma, uma estudante de 17 anos da Escola Secundária Stuyvesant, acadêmica rigorosa da cidade de Nova York. Emily nunca teve que usar letra cursiva na escola e, por isso, acabou aprendendo a escrever à mão por conta própria.

Outros motivos apontados por Matthews (2020, p. 2), a partir da fala de Carmem Fariña, ex-chanceler das Escolas de Nova York, dizem respeito à automatização da escrita à mão ser mais rápida e eficiente do que a feita no computador e de que a visão mais global das unidades do discurso está mais presente quando se escreve à mão:

As escolas da chanceler Carmen Fariña distribuíram um manual sobre o ensino da escrita cursiva em setembro [de 2017] e incentivam os diretores a usá-lo. No manual, cita-se uma pesquisa que sugere que ter fluência cursiva ajuda os alunos a escrever tarefas de escrita, como ortografia e construção de sentenças, porque eles não têm que pensar tanto sobre a formação de letras.

O excerto remete ao aspecto social da ortografia, com suas normas que aparecem quando um texto se torna público. Esse aspecto nos faz retomar o pensamento de Chartier (2010), de que a tecnologia da impressão enformou a escrita, transformou-a em algo estável, monumental e controlado, feita para seguir as normas ditadas pelo corpo social, e nos impulsionou a acreditar que a escrita, seja ela de que forma for, é extensão do homem.

Em consonância com os efeitos da escrita nos processos de aquisição, Chartier (2010) enfatiza que, no computador, o espaço de escrita é a tela, ao contrário do que ocorre quando o espaço da escrita são as páginas em branco de um papel. A escrita eletrônica, digamos assim, possibilita a quem escreve, a cada momento, a criação de infinitas formas de escrita, possibilita fazer links com vários tipos de textos, o chamado hipertexto, conforme Chartier (2010).

Além do mais, Chartier (2010) afirma que é preciso ter a compreensão do computador como um suporte multimodal que aguça a percepção das crianças sobre a 
escrita alfabética por oferecer imagens dinâmicas, som, comunicação on-line, dentre outros. Lévy (1998), por sua vez, considera que o uso da tecnologia no âmbito da educação faz com que os estudantes participem mais ativamente do processo de ensinoaprendizagem.

Em parte, Lévy (1998) discute o ensino da escrita pelo método convencional e o uso das ferramentas digitais em substituição ao atual modelo de letramento. Como método reflexivo, o referido autor rememora o que acontecia quando as pessoas começaram a fazer uso das calculadoras. Antes, todos faziam cálculos mentais. Hoje, poucas pessoas ousam uma conta sem ter uma calculadora ao lado. Nesse sentido, logo as pessoas irão escrever e ler tendo como principal ferramenta o computador.

Para Lévy (1998), todos os estudantes têm habilidades extraordinárias para usar as ferramentas digitais, porém, a pergunta seminal do pesquisador é: os professores têm a mesma habilidade? Eles conhecem as ferramentas digitais tão bem quanto as crianças? Nessa ótica, o professor precisa se capacitar, afinal, ele só pode ensinar aquilo que conhece.

De acordo com Braggio (1992), na linguagem oral os nossos ouvidos estão atentos aos significados decorrentes da cadeia sonora. Por sua vez, na escrita, a visão é acionada para decifrar a linguagem. Em aquisição da linguagem escrita esta é a primeira descoberta que a criança faz, a de que um sinal gráfico não remete ao referente, mas à uma forma sonora da linguagem que o representa. Para nós, adultos alfabetizados, essa diferença entre língua oral e língua escrita parece óbvia, porém, a decifração do código escrito por parte da criança representa um salto no conhecimento do aprendiz.

Sendo assim, assinala Braggio (1990), a relação da criança com a escrita é uma relação de tentar decifrar o que significa os "desenhos" que os adultos leem. A criança mais do que ninguém fica surpresa com a imagem gráfica das palavras, que as impressiona significativamente, afinal, as letras são para elas um objeto permanente de uso, são objetos sólidos.

Ao que nos parece, o grande impasse para a efetivação do letramento digital deve-se às escolas, que ainda veem o aluno apenas como um depósito de informações que precisa ser preenchido. A seguir, ao problematizar a realidade brasileira, apresentamos uma discussão sobre esse tópico.

\section{Abolição da escrita à mão nas escolas do Brasil?}

No Brasil, conforme assinala Soares $(2002,2020)$, é ainda insistente o debate sobre a diferença entre alfabetização e letramento, assim como a discussão sobre qual tipo de letra usar na alfabetização, letra bastão/maiúscula ou letra cursiva/letra de mão. A referida estudiosa recomenda que, mais do que colocar os conceitos de alfabetização e letramento, é preciso valorizar as práticas sociais que envolvem os sujeitos envoltos no uso da língua escrita.

Com relação ao uso do computador nas atividades de alfabetização, Soares (2002) afirma não ter dúvidas de que o uso do computador auxilia a criança a compreender a dimensão de comunicação sócio-cultural da escrita, isto é, a escrita no computador ligado à internet possibilita que a criança aprimore essa técnica, além de fazer ampliar o alcance dos letramentos múltiplos com maior rapidez e facilidade.

No que se refere à abolição da escrita à mão nos processos de alfabetização, reapresentamos o que pensa Soares $(2020$, p. 1): 
[...] é preciso reconhecer que, se antigamente era realmente necessário que a criança dominasse a cursiva, e eram comuns as aulas de caligrafia, hoje em dia cada vez menos esse ensino é necessário; mas é importante que a criança pelo menos saiba ler um texto em letra cursiva, porque ela vai se deparar muitas vezes com textos em cursiva.

As afirmações de Soares (2002 e 2020) fazem com que voltemos ao assunto escrita cursiva versus escrita bastão e nos remete ao fato de se enfatizar na alfabetização qual a melhor forma de se escrever. Segundo Bernardes (2013, p. 79),

A letra cursiva está associada, inicialmente, aos métodos, como por exemplo, o analítico ou global de alfabetização, que utilizam a letra cursiva para facilitar a memorização do texto, sentença ou palavra, que é estratégia básica nesse método (BRASIL, 2008, p. 30). O uso de letras de forma maiúsculas apoia-se na ideia de serem mais fáceis de reconhecer, contar e de fácil traçado.

Quando se compara o ato de escrever à mão com o de teclar, este parece ser um gesto menos trabalhoso por parte da criança, pois, a princípio, ela precisa coordenar apenas a intensidade do toque no teclado, uma vez que não pode fugir aos nossos olhos que o período de alfabetização inicial é também um momento de coordenação e direcionamento dos gestos motores por parte dos pequenos.

Assim, apertar uma tecla é uma ação muito mais suave do que fazer malabarismos com o lápis para desenhar as letras. Para quem já domina o processo de escrita é algo natural, mas é preciso se colocar no lugar de quem não tem a técnica da escrita e que todo o movimento para registrar uma letra pode ser doloroso, embora não descartemos que o próprio aprendizado do controle da intensidade para teclar no computador mobilize habilidades específicas que a criança também não domina, ou seja, identificar quais teclas apertar e o quanto apertar são aprendizados necessários para as crianças escreverem no computar. As escolas brasileiras não superaram ainda a discussão sobre o uso ou não a letra cursiva na alfabetização. Entretanto, segundo Padgurschi (2020), desde 2017,

Não existem sinais de total abandono da letra cursiva no Brasil, o que já acontece em países europeus e nos EUA, mas ela já não é prioridade absoluta de ensino e é aprendida em um segundo momento em parte dos colégios. No colégio Santa Amália, na Saúde (zona sul), as salas do primeiro ano do ensino fundamental são decoradas com letras bastão, também tidas como letras de imprensa.

Padgurschi (2020) comenta que tanto no Colégio Santa Amália quanto em outras tantas escolas de São Paulo, a ideia é alfabetizar a criança com letra bastão e, nessa escolha, contar com muitas atividades no computador. Também, o referido autor afirma que os professores paulistas acreditam que a letra bastão ou de imprensa traz o mundo real da criança para a escola, sobretudo porque a criança brasileira passa muito tempo em contato com computadores, tabletes e telefones celulares. Nesse sentido, os professores afirmaram à Padgurschi que, após a criança estar plenamente alfabetizada, ela poderá aprender a letra cursiva na força que esse modo de representação ainda tem (tiver) na cultura brasileira.

Ainda na mesma reportagem, afirma-se que há resistências ao uso do computador e da letra bastão nos processos de alfabetização em algumas escolas paulistas. De acordo com Padgurschi (2020, p. 3), "a linha pedagógica dessas escolas, a 
primeira fundada há 108 anos, segue o que consideram tradição, 'sem apelos ao modismo', e baseia-se em pesquisas que indicam que a letra manuscrita estimula a cognição e a reflexão".

Como diz Soares (2020), toda essa discussão parece ser muito inovadora para os brasileiros. Ao que nos parece, ainda há muito para se discutir e para ser feito no Brasil. Conforme Libâneo et. al. (2011), não há nas escolas computadores suficientes para todas as crianças, os professores lidam pouco com a tecnologia em sala de aula, talvez por terem poucos recursos ou por pouco saberem manusear as ferramentas tecnológicas. Assim, temos ainda no Brasil escolas diferentes para grupos diferenciados da sociedade. Em algumas escolas, há computadores e iniciativas para que o processo de alfabetização seja feito a partir da escrita na tela, mas, na maioria das escolas brasileiras, ainda faltam muitos recursos para que elas funcionem bem.

No atual contexto brasileiro de letramento ${ }^{5}$, os profissionais de educação precisam desenvolver estratégias pedagógicas mais eficazes para bem relacionarem as questões de alfabetização, letramento e letramento digital de modo a preparar os alunos para atuarem adequadamente e plenamente no Século do Conhecimento. Porém, de acordo com Soares (2002), o que majoritariamente ocorre no sistema educacional brasileiro é apenas o ensino da cópia de palavras na fase de alfabetização, o que pode fazer com que os alunos pratiquem a escrita de forma mecânica, sem refletir na construção das sílabas, das palavras e do texto. Podemos dizer que a mecanização do processo de alfabetização pode ocorrer também a partir do uso do computador, fato que um estudo acurado poderá comprovar.

\section{Considerações finais}

Esperamos ter deixado claro ao longo de nosso texto a instauração de uma discussão sobre alfabetização pela via digital ou convencional e que, mais do que pensar sobre a forma da letra a ser utilizada, se bastão ou cursiva, é preciso pensar no aspecto da língua. Se formos pela via de Saussure (1996), adotaremos o ponto de vista de que a escrita é a testemunha da história. A língua [materna ou de outro país, L1 ou L2 etc.], na maioria dos casos, é conhecida por meio da escrita, eis uma das razões pelas quais certas línguas-culturas desapareceram e não se deixaram ser revitalizadas, pois não tinham uma escrita que fizesse "perpetuar" a história de um povo ou que fizesse essa memória tomar novamente corpo.

Mesmo sabendo que a tradição independe da escrita, esta, porém, impede aquela de ver-se o prestígio que possui, afinal, ainda com base em Saussure (1996), na maioria dos indivíduos, a imagem gráfica das palavras impressiona consideravelmente.

Isto significa que o universo discursivo em que a criança está inserida é determinante de sua fala e de sua escrita e, por isso mesmo, condição de sua interpretação. Há muito para se discutir sobre a aquisição da escrita via ferramentas digitais, isto é, se a forma da letra influencia de alguma forma o processo de aquisição da escrita e como podemos potencializar na escola essa influência, por exemplo. Segundo De Lemos (1998), a natureza dos aspectos gráficos da escrita e o seu papel no processo de aquisição talvez possam ser mais bem compreendidos se buscarmos em novas formas de notação, que não a alfabética, cursiva, elementos para uma reflexão.

\footnotetext{
${ }^{5}$ Recentemente, em dezembro de 2019, o Ministério da Educação (MEC) lançou o programa "Literacia Familiar", que diverge dos estudos sobre letramentos apresentados neste artigo. Para maiores informações consultar o site: $<\mathrm{http}$ //portal.mec.gov.br/busca-geral/12-noticias/acoes-programas-e-projetos-637152388/83281-mec-lancaprograma-conta-pra-mim-para-incentivar-a-leitura-de-criancas-no-ambiente-familiar>.
} 
Pela concepção de De Lemos (1998), independente da forma da letra, o que está em jogo, aliás, o que não se perde, é a interação dialógica que faz emergir no sujeito traços de sua relação com o Outro, responsável pelo funcionamento linguísticodiscursivo. Isto implica dizer que a criança, tanto na fala quanto na escrita, será/está vinculada ao Outro, uma vez que este representa - assim com a língua - polos de uma estrutura, a saber: o polo do Outro, o da escrita e o da criança.

Adquirir a língua escrita não é, de modo algum, tarefa simples. Nas línguas que seguem a escrita alfabética, por exemplo, a criança precisa descobrir a correspondência fonema/grafema, falsa correspondência, conforme Saussure (1996), para dar conta de fazer exercícios de fixação das letras. Da mesma forma, nas línguas que possuem formas diferentes de registros, as crianças precisam entender as correspondências entre símbolos escritos e palavras faladas. Segundo Braggio (1992), no caminho da aquisição da escrita alfabética em português, a criança, quando escreve, deixa em evidência a insuficiência do sistema som-letra para reproduzir os sons da sua própria fala.

Tentamos demonstrar ao longo do texto que a forma da escrita é culturalmente determinada e que a criança adquire a escrita a partir da relação que ela mantem com essa forma de linguagem, ou seja, a escrita, assim como outros elementos culturais, atua na formação da subjetividade e é por ela modificada, pois há uma forma peculiar de escrita, um modo subjetivo de escrever, isto é, um sujeito que surge desse processo (DE LEMOS, 1998). Assim, independentemente de qual escrita que se apresente para ser adquirida, o mais importante é o como fazer essa aquisição acontecer, os modos de produção desse processo devem ser o foco da escola.

Além do mais, em nosso texto não direcionamos a discussão sobre $o$ envelhecimento do atual modelo de letramento e muito menos tivemos a intenção de avaliar o risco de substituição do letramento alfabético pelo digital. A nossa verdadeira intenção foi a de mostrar aspectos dos dois conceitos/modos de alfabetização/letramentos, como acontecem hoje nos EUA. Do nosso percurso reflexivo, é possível observar que o modelo alfabético está servindo de apoio para a aprendizagem do letramento digital.

Por fim, a escola não pode negar o crescente aumento na utilização das novas ferramentas tecnológicas como computador, internet, cartão magnético, caixa eletrônico etc. em nosso cotidiano, fator que impulsionou algumas escolas a adotarem a escrita digital como base para o processo de alfabetização. Também, por outro lado, ainda acreditamos que a caneta e o lápis continuarão tendo a força utilitária que exercem em nossa sociedade, funções que apontam ainda para a necessidade da escrita cursiva em nossas atividades sociais por um bom tempo.

\section{Referências}

BARTON, D.; HAMILTON, M. Local Literacies: Reading and writing in one community. London, Routledge, 1998.

BERNADES, F. F.. Alfabetização na concepção das professoras dos anos iniciais do ensino fundamental. Rio Grande do Sul, 2013, 101f. Dissertação (em Educação) Faculdade de Educação, Universidade Federal do Rio Grande do Sul.

BIBIANO, B.. Na Finlândia, escolas trocam letra de mão por digitação. 18 dez. 2014 Disponível em: <http://veja.abril.com.br/educacao/na-finlandia-escolas-trocam-letra-demao-por-digitacao/>. Acesso em: 26 fev. 2020. 
BRAGGIO, S. L. B. Aquisição da linguagem escrita no ambiente social e sua relação com o processo de alfabetização. Letras em Revista. v. 1, n. 3/4, p. 251-301, 1990.

- Leitura e alfabetização: da concepção mecanicista à sociopsicolinguística. Porto Alegre: Artes Médicas, 1992.

Linguística e ensino: do virtual ao real. In: FERNANDES, E. M. da F.; SOUSA FILHO, S. M. Leitura: Ações de Mediação Pedagógica, Campinas, SP: Pontes Editores, 2015. p. 137-148.

BRASIL. Instituto Nacional de Estudos e Pesquisas Educacionais Anísio Teixeira INEP. Programa Internacional de Avaliação de Estudantes (Pisa). Disponível em: $<$ http://portal.inep.gov.br/pisa>. Acesso em: 23 jun. 2020.

BRASIL. Ministério da Educação - MEC. Disponível em: $<$ http://portal.mec.gov.br/busca-geral/12-noticias/acoes-programas-e-projetos637152388/83281-mec-lanca-programa-conta-pra-mim-para-incentivar-a-leitura-decriancas-no-ambiente-familiar>. Acesso em: 19 dez. 2019.

CHAO, M. L.. Caligrafia em Extinção. 01 jan. 2012. Disponível em: < http://www.revistaplaneta.com.br/caligrafia-em-extincao/>. Acesso em: 26 fev. 2020.

CHARTIER, R. Escutar os mortos com os olhos. Estudos Avançados. São Paulo, v.24(69), n. 1, p. 6-30, jan. 2010.

DANTE, M. N.. Cadernos de Rafaela: análise do desenvolvimento de um vocabulário gráfico para letra manuscrita nos três primeiros anos do Ensino Fundamental. Rio Grande do Sul, 2019, 75f. Trabalho de Conclusão de Curso - Pedagogia, Universidade Federal do Rio Grande do Sul.

DE LEMOS, C. T. G. Sobre a aquisição da escrita: algumas questões. In: ROJO, R. (Org.). Alfabetização e letramento: perspectivas linguísticas. Campinas/SP: Mercado de Letras, 1998. p. 13-32.

FÉVRIER, J. G. Histoire de l'écriture. Paris: Payot, 1948.

GONÇALVES, D.. A origem do alfabeto cursivo. 05 mai. 2011. Disponível em: $<$ https:/ciberduvidas.iscte-iul.pt/consultorio/perguntas/a-origem-do-alfabetocursivo/29728>. Acesso em 26 fev. 2020.

GUIMARÃES, J. O.; SILVA, S. A.. Design e educação: uma estratégia interdisciplinar para a escrita manual cursiva na era dos nativos digitais. In: $12^{\circ} \mathrm{P} \& D 2016$ Congresso Brasileiro de Pesquisa e Desenvolvimento em Desing, 2016, Anais do $12^{\circ} \mathrm{P} \& \mathrm{D}$, Belo Horizonte, 2016, p. 2785-2794.

HENNELLY, W. The return of cursive writing: master stroke or exercise in nostalgia? Disponível em: $\quad<$ http://usa.chinadaily.com.cn/opinion/201703/15/content_28559229.htm>. Acesso em: 26 fev. 2020.

LÉVY, P. As tecnologias da inteligência: o futuro do pensamento na era da informática. Tradução de Carlos Irineu Da Costa. São Paulo: Editora 34, 1998. 
LIBÂNEO, J. C. et al. Concepções e práticas de ensino num mundo em mudança: diferentes olhares para a Didática. Goiânia/ Ceped: Ed. PUC Goiás, 2011.

MAGALHÃES, J. Cinco questões a Roger Chartier. Tradução de Mariana Gomes da Costa. Cadernos de História da Educação, Rio de Janeiro, v. 13, n. 2, p. 419-422. jul./dez. 2014.

MARCONI, M. A.; LAKATOS, E. M.. Fundamentos de metodologia cientifica. $5^{\text {a }}$ edição. São Paulo: Atlas, 2003.

MATTHEWS, K.. Cursive is making a comeback in American elementary schools. Disponível em: $<$ http://www.businessinsider.com/cursive-making-comeback-americanschools-2017-3-2>. Acesso em: 26 fev. 2020.

PADGURSCHI, D.. Escolas já começam a alfabetizar crianças 'com letras da internet'. Disponível em: <http://www1.folha.uol.com.br/educacao/2017/04/1871992escolas-ja-comecam-a-alfabetizar-criancas-com-letras-da-

internet.shtml?cmpid=facefolha>. Acesso em: 26 fev. 2020.

PEDROZA, N.; NICOLAU, M. Toque na tela: a revolução da tecnologia Touchscreen nas Mídias Móveis. Temática, Paraíba, v. 11, n. 11, p. 68-83, nov. 2015.

SAUSSURE, F. de. Curso de Linguística Geral. Organizado por Charles Bally e Albert Sechehaye. Tradução de Antônio Chelini, José Paulo Paes e Izidoro Blikstein. 25 ed. São Paulo: Cultrix, 1996.

SILVA, P. H. O papel do imperativo e da imperatividade na aquisição do português brasileiro. Goiás, 2018, 113f. Dissertação (Dissertação em Letras e Linguística), Universidade Federal de Goiás.

SOARES, M. B. Novas práticas de leitura e escrita; letramento na cibercultura. Revista Educação e Sociedade. Campinas, v. 23, n. 81, p. 143-160, dez. 2002.

- Magda Soares responde. Ceale/FAE/UFMG. Disponível em: $<$ http://www.ceale.fae.ufmg.br/pages/view/magda-soares-responde-5.html $>$. Acesso em: 23 jun. 2020.

SOUSA FILHO, S. M.. Reflexões sobre a aquisição de língua pela criança Xerente. In: Braggio, S. L. B. e Sousa Filho, S. M.. (Org.). Linguas e Culturas Macro-Jê. 1ed.Goiânia: Editora Vieira, 2009, v. 1, p. 297-314.

SOUSA FILHO, S. M.; SILVA, P. H. O CLG de Saussure como base para o redimensionamento das pesquisas em aquisição de linguagem. In: Clemilton Lopes Pinheiro e Maria Hozanete Alves de Lima. (Org.). Diálogos: Saussure e os estudos linguísticos contemporâneos (VOLUME III). 1 ed.Natal: EDUFRN, 2017, v. 1, p. 237254.

THEISEN, J. de M.. Novos Estudos dos Letramentos: novas práticas de leitura e escrita. Entrepalavras, v. 4, p. 164-179, 2014. 
YOW, C. State law will require schools to teach cursive writing. Disponível em: $<$ http://www.trussvilletribune.com/2017/03/05/state-law-will-require-schools-to-teachcursive-writing/>. Acesso em: 26 fev. 2020.

Recebido em 20 de maio de 2020

Aceito em 26 de junho de 2020 